\title{
Measuring the Diversity of Household Spending Patterns
}

\author{
Andreas Chai* \\ Nicholas Rohde* \\ Jacques Silber**
}

\begin{abstract}
Households tend to diversify their spending across a wide range of goods and services as they become more affluent. Recently, there has been growing interest in understanding the precise manner in which this spending diversification process takes place. We review what facts are known about this process and the underlying behavioral tendencies that are thought to drive it. In addition, we clarify the relationship between different approaches to measuring the level of spending diversity. A number of indices are employed including measures based on joint probabilities, distances and the concept of entropy. Using UK household spending data, we show the extent to which these measures deliver different results and shed light on the nature of behavioral heterogeneity.
\end{abstract}

JEL codes: C46, D12

Keywords: Spending Diversity, Engel’s Law, Behavioral Heterogeneity

August 2013

Not to be quoted without the authors' permission.

* Griffith Business School, Gold Coast Campus, Griffith University, Qld, 4222, a.chai@griffith.edu.au, n.rohde@griffith.edu.au +61 7555 28607, +61 755528068

** Bar-Ilan University, Israel, and Senior Research Fellow, CEPS/INSTEAD, Esch-sur-Alzette, Luxembourg. 


\section{Introduction}

Household spending is the core driving force of economic growth: it represents more than half of GDP in most developed economies. As their wealth grows, households tend to rapidly alter their spending patterns through which a wide variety of new goods enters the consumption basket (Prais, 1953; Jackson, 1984). The growth in the variety of available goods is seen as an important, welfare-enhancing feature of modern economic development (Romer, 1990, Grossman and Helpman, 1991; Barro and Sala-i-Martin, 1995), and has important implications for a range of economic issues. For example, in growth theory a longstanding conjecture exists that changes in the industrial composition of growing economies are caused by changes in the composition of household demand (e.g. Kuznets, 1973; Foellmi and Zweimüller, 2008). Moreover, Engel curves are also of great relevance in the measurement of inflation (Bils and Klenow, 2001A) and measuring the welfare effects of tax policy (Banks et al., 1997).

Yet the grave reality is that current state-of-the-art models of household demand still fail to explain most of the observed variation in household consumption behavior (Lewbel, 2008). At the core of this problem is the issue of heterogeneity: two households with the same observable socioeconomic and demographic characteristics and facing the same prices for goods tend to possess very different spending patterns. A number of scholars have begun considering how behavioral heterogeneity can be modeled (e.g. Calvet and Common, 2003). This is defined as variation in the household spending patterns that is not accounted for by observable variable and is driven by actual differences in actions and tastes, rather than sampling and measurement bias. This new direction represents a significant shift away from treating all modeling errors as measurement errors and seriously considering how the large and systematic error may to some extent represent 'true' structural heterogeneity (Lewbel, 2005). At the same time, research faces a number of hidden methodological pitfalls and can be criticized for being relatively ad hoc via imposing harsh restrictions on the heterogeneity of consumer demand (Hildenbrand and John, 2003), as well as downplaying the possibility of error arising due to misspecification.

We suggest that a more realistic starting point to accounting for behavioral heterogeneity in household spending patterns can be attained by considering the stylized facts about how households diversify their spending as they become more affluent. As defined by Theil (1967) and Theil and Finke (1983), the diversity of consumer demand is measured by the entropy of their budget shares. At low levels of income household spending is both highly concentrated on food spending, as well as highly homogenous (there are relatively small observed differences between households). As household income rises, spending diversity rises and the observed differences in household spending patterns become larger. In this sense, the tendency in which households diversify their spending patterns beyond food spending can be seen as a necessary (but not sufficient) condition needed to observe the growth of heterogeneity. Understanding this behavioral process in its own right can thereby shed light on how heterogeneity emerges as household income rises.

Furthermore, empirically measuring the level of spending diversity by households can also deliver a better understanding of heterogeneity. In this regard, we review the statistical approaches used to measure the diversity of spending patterns that provide information about how dispersed household spending shares are across different categories. To date, a range of measures have been used to measure spending diversity. As far as we are aware, no definitive statement exists discussing the differences between these measures, and to what extent spending diversity varies across these different measures. To this end, we examine the relationship between these different measures of spending diversity using UK household expenditure data. In addition 
we highlight various methods for measuring diversity relative to a non-equal reference distribution. This is an important issue as it is rare for boundary values to be observed in household spending diversification levels: Households do not concentrate all their spending on one category, nor do they spread it evenly across all existing spending categories. Therefore it is worth considering how diversity can be ascertained when the benchmark is not uniform across different diversity measures. This paper reviews a number of different approaches to benchmark diversity respectively based on the concept of entropy, the Euclidian distance and the absolute value function.

The paper is structured as follows. Section 2 discusses the ongoing effort to grapple with heterogeneity in household spending patterns, while Section 3 reviews the known stylized facts that describe the manner in which household spending patterns evolve as income rises and discusses the behavioral household tendencies that could account for the diversification process. Section 4 then considers the statistical approaches to measuring diversity in household spending, while Section 5 investigates issues surrounding the benchmarking levels of household spending diversity within a population of households. Section 6 concludes.

\section{Heterogeneity and the development of demand analysis}

Today, the literature on household spending is vast and contains a range of relatively specialized subfields which are delineated by their focus on particular types of spending, such as tourism spending or food expenditure (Slotje 2009). Moreover, household spending patterns play a role in almost every major field of economics, such as public finance and agricultural economics. The predominant method used in applied studies of demand has been the demand systems approach, in which a system of equations is used and the dependent variable is household spending on a particular good (usually expressed as a budget share), while the dependent variables are the relative prices of other goods, household income (discussed below) and the household's demographic characteristics. The core theory underpinning this approach is based on a view that these expenditures are an outcome of a single, representative household that maximizes its utility in each period by spending on the observed categories according to a linear budget constraint. ${ }^{1}$

Given the prominence of this literature and its ability to attract some of the "best minds in economics” (Deaton, 1987; Clements and Selvanathan, 1994), it may seem peculiar that state-ofthe-art models of household demand still fail to explain most of the observed variation in household consumption behavior (Lewbel, 2008). We consider below two interrelated reasons that may account for this state: firstly; the problem of heterogeneity in spending data (in this section) and the adherence to neoclassical demand theory which strictly focuses on explaining change in spending behavior in terms of price and income effects (in the next section).

The first reason is that much of the literature has been grappling with a fundamental problem: how to deal with the immense amount of heterogeneity observed in household spending patterns. As noted in James Heckman's 2001 Bank of Sweden Nobel Memorial Lecture in Economic Sciences, one of the most important discoveries emerging from micro-econometric research was evidence of the pervasiveness of heterogeneity and diversity in economic life (Heckman, 2001). Heterogeneity is defined as the variation in household spending that cannot be accounted for in

\footnotetext{
${ }^{1}$ A number of assumptions in this literature are made about the nature of preference and the budget constraint, for more details see Deaton and Muelbauer (1980A). A particularly interesting and testable assumption is the "adding up" restriction which derives from the assumption that the budget constraint is linear. It implies that the sum of income elasticities, when weighted by the respective budget share of each spending category, add up to one.
} 
household spending patterns. To borrow the example from Lewbel (2005) and Browning and Carro (2005), suppose we have a dependent variable $Y$ such as household purchases of a particular good and a vector of covariates $X$, such as the prices of substitutes, the income of households and their demographic characteristics. Heterogeneity is defined as the variation in $Y$ that is not explained by $X$. There are of course many sources of heterogeneity, such as unobserved differences in prices faced by households or measurement error. Behavioral heterogeneity refers to variation that reflects difference in the household actions and tastes, rather than measurement errors.

The second reason is that, since the 1930s, scholars have pursued the testing of hypotheses closely linked to microeconomic theory that strictly focuses on studying the effects of price and income within the confines of representative agent models (Blaug, 1992; Barnett and Serletis 2008). Previously in the $19^{\text {th }}$ century, studies were more inductive in nature in that they did not explicitly test a hypothesis, but rather focused on uncovering basic stylized facts about the manner in which household spending patterns evolved as household income grows (discussed below). The direction of research changed drastically with the emergence of neoclassical demand theory in the late nineteenth century (Mirowski and Hands 2006). The core theoretical framework is that average household expenditure on a particular good can be modeled as a result of the actions of a single representative utility maximizing consumer.

This approach has been defended on the basis that while no individual consumer may actually possess the preferences of ideal consumers, it is still possible to study average consumption data, where disturbing factors have been averaged out (Brown and Deaton 1972). As Hicks put it "the preference hypothesis only acquires a prima facie plausibility when it is applied to statistical average. To assume that the representative consumer acts like an ideal consumer is a hypothesis worth testing; to assume that an actual person, the Mr. Brown or Mr. Jones, who lives around the corner, does in fact act in such a way does not deserve a moment's consideration” (Hicks 1956:55). As a result, there has since been little concern about what alternative theoretical approaches could be adopted to account for household spending patterns, even though the inadequacy of the theoretical framework is widely acknowledged (Houthakker 1950:2,Prais 1953: 88, Deaton and Muellbauer 1980:323).

In the following we briefly outline three different types of heterogeneity: i) observed variation in household spending for a given good across different income levels, which is linked to heteroscedasticity around Engel curves; ii) observed variation across different goods, which is linked to the issue of the choice of functional forms used to estimate Engel curves across different types of goods; and iii) observed variation of household spending overtime which is linked to the issue of separability and stability over time of household preferences.

\subsection{Heterogeneity over income levels}

The issue of heterogeneity first emerged in the parametric estimations of Engel curves, which relates household expenditure to household income. In the first parametric estimate of household spending patterns, Allen and Bowley (1935) observed that the error terms in these early models were quite large. These were attributed to omitted variable bias and the inability for the linear functional form to capture heterogeneity in household spending patterns in two different dimensions: across income levels, as well as across different goods. Concerning the former, the fact that the variance of household expenditure data increases with income has been attributed to survey bias as a relatively lower proportion of rich consumer tends to participate in spending surveys, violating the assumption that households face the same price for goods, unobserved 
demographic differences, as well as differences in tastes (Brown and Deaton 1972:1172). It is also worth noting that this literature typically uses total household expenditure as the proxy for income, which tends to ignore the role that savings play in influencing household expenditure. ${ }^{2}$

\subsection{Heterogeneity over goods}

Concerning the heterogeneity of spending patterns across different goods, the early literature focused on an exhaustive search for a functional form that can best handle this heterogeneity. Here there has always been a methodological preference to use a common functional form to estimate Engel curves across all goods and service, although the estimated income elasticities across expenditure categories were quite different (Brown and Deaton 1972). This eventually led to the emergence of log-linear and finally nonlinear models by the 1950s (Working, 1943; Prais, 1953; Prais and Houthakker, 1955). More recently, this issue has resurfaced in relation to estimating the rank of demand systems and how many different shapes of Engel curve exist across different goods within an estimated system of demand equation (Lewbel 1991, Blundell and Stoker 2005, Barigozzi and Moneta 2012). In particular, several theoretical contributions have established that the rank of exactly aggregable demand systems must be three or less in order to be consistent with utility maximization (Gorman 1981, Lewbel 1991). The rank is the dimensions of space spanned by the Engel curves. If all Engel curves can be appropriately estimated with a single linear term, then the rank of the system is one. Increasing the rank of the system involves adding more terms to capture the effect of income on spending, which delivers a better goodness of fit and is better suited for estimating non-homothetic preferences (Banks et al 1997).

\subsection{Heterogeneity over time}

With the emergence of reliable panel data on consumption, a third type of heterogeneity related to the time dimension is also receiving attention in the literature. Demand systems typically make the assumption that household preferences are separable over time. This implies that the amount spent by a household on one good in one time period does not influence how much it spends on the good in the next time period. Clearly such assumption cannot be made in relation to durable goods, which are consumed over relatively long timespans. Recent evidence from panel data on household expenditure suggests that such lags play an important role with such expenditure categories as takeaway food, clothing, alcohol and (Browning and Collado 2007). Elsewhere, studies of Revealed Preference theory have also developed a number of methods to test the extent to which time series consumption data is 'rational' and consistent with utility maximizing behavior (Blundell 2005).

\subsection{Future directions}

To progress, there has been a growing push to consider how the heterogeneous nature of individual household preferences may have implications for understanding the aggregated relationships (Blundell and Stoker, 2005; Calvet and Common, 2003). An early contribution included Hildenbrand (1994) who showed that certain restrictions on the income distribution can lead to the emergence of particular properties in aggregate demand, such as the law of demand. Other seminal contributions by Grandmont (1987; 1992), Quah (1997) and Kneip (1999)

\footnotetext{
${ }^{2}$ Life cycle studies of consumption show a very strong correlation between income and savings (Attanasio 1999).
} 
investigate how the heterogeneity of household spending behavior can explain the insensitivity of aggregated budget shares to prices and income. Elsewhere, Lewbel (2001) has also considered under what types of behavioral heterogeneity the conditional mean demand for a good is consistent with standard utility maximization theory. However, this effort is relatively new and several methodological debates are ongoing (see inter alia de Villemeur, 1998; Hildenbrand, 1998; Hildenbrand and Kneip, 1999). Moreover, the main method used to model heterogeneity thus far has involved imposing severe restrictions on the nature of heterogeneity in household spending patterns. Many researchers have adopted a Random utility maximization framework (e.g. Calvet and Common, 2003), which implies that the random heterogeneity components that affect household demand cannot be generally additive, as is typically assumed in demand models (Beckert and Blundell, 2008).

\section{Stylized Facts about the diversification of demand and their theoretical implications}

A snapshot of the long run evolution of household spending patterns in the US is provided in Table 1. In the following, we review three known stylized facts about household spending patterns and alternative theoretical accounts that can explain these stylized facts. Taken together, these stylized facts underline how heterogeneity tends to emerge in household spending patterns as household income rises. This suggests that a better understanding of how households diversify their spending as they become more affluent could play a key role in building a comprehensive theory of household spending patterns.

\section{Stylized Fact 1: At low income levels, spending diversity is low as food expenditure dominates spending}

The starting point to understanding the diversification process is to first gain a perspective on how and when undiversified and homogenous household spending patterns exist. A considerable amount of evidence suggests that among low income households, consumption patterns are homogenous. According to a recent survey of the world's poorest, spending on food represent about 50 to 70 per cent of the budget (Banerjee and Duflo, 2007). From a historical perspective, it is remarkable that Engel's 1856 analysis of the poor, working class Belgian households also reports expenditure on food to be between 70 to 62 per cent. ${ }^{3}$ Moreover, the dominance of food expenditure among the poor is found to also hold in cross-country comparisons of per capita consumption collected from over thirty countries between 1960 and 1982 by Clements and Chen (1996). The authors found that the average food expenditure for 12 Least Developed Countries (LDCs) was about 40.44 per cent of total per capita consumption. In contrast, the same budget share among 18 OECD countries was 29.59 per cent - a difference of about 10 per cent. In terms of the theoretical significance of this homogeneity, it seems to reflect how the human phylogeny shapes household consumption patterns. In particular, there is little doubt that biological evolution has endowed individuals with a set of universal basic needs, of which the most elementary is the need for nutritious materials necessary for survival, such as food and water (Witt, 2001; Chai and Moneta, 2012).

Stylized Fact 2: As household income grows, spending diversity increases via reduction in the budget share of food spending, and increase in non-food expenditure

\footnotetext{
${ }^{3}$ It should be noted the Engel's definition of food included alcohol and tobacco (Chai and Moneta, 2010).
} 
Engel's Law states that the budget share dedicated to food declines as household income rises, (Engel, 1857; Houthakker, 1957). In terms of the magnitude of this effect, Banerjee and Duflo (2007) state that a one percent increase in overall expenditure translates into about a two-thirds of a percent increase in the average population budget share spending on food by a poor family. Elsewhere Thomas and Strauss (1997) found an elasticity of demand for food with respect to expenditure per capita of about a quarter for the poorest urban households in Brazil. On a more aggregate perspective, evidence for Engel's law can also be found when comparing the spending patterns of poor and rich countries (Houthakker, 1957). Such consistent evidence has also led to a formulation of a "strong version" of Engel's Law that is proposed by Theil et al. (1989): when income doubles, the budget share dedicated to food expenditure declines by 10 percentage points (Clements and Selvanathan, 1994).

\section{Stylized Fact 3: individual household spending becomes more diversified as income rises}

A longstanding conjecture is that rising income generates a greater degree of dispersion of spending in that wealthier households distribute their total spending more evenly across the range of available spending categories. ${ }^{4}$ Theil and Finke link this growing dispersion to Engel's law since it is because the demand for food declines as incomes rises and other goods play a more prominent role in the consumers budget, that we should expect an increasing diversity of spending as income increases (Theil and Finke, 1983). However, this is in fact an Addendum to Engel's Law, as an increasingly even distribution of spending across categories also implies that all non-food spending categories will also eventually attain the same share of spending (Chai and Moneta, 2012).

Evidence for a positive correlation between household income and the dispersion of household spending has been found in a number of studies of cross-country demand analysis (Theil and Finke, 1983; Falkinger and Zweimüller, 1996; Clements et al., 1996b). For example, in a study featuring 91 consumption items across 57 countries, Falkinger and Zweimüller (1996) found a strong positive relationship between a country's per capita income and the number of items that it consumes. The poorest country in the sample (Tanzania) consumed 19 out of a possible 91 items, which is much lower than the 90 products consumed by the richest country in the sample (United States). At the household level, Chai and Moneta (2012) found some support for the hypothesis that the diversification rate of household spending patterns reaches a saturation level at certain levels of income. These authors also found that over time, the diversification levels of households situated in the lowest income decile appeared to be converging with diversification levels observed in high income households.

\subsection{Accounting for the emergent nature of behavioral heterogeneity}

Given that household spending patterns are relatively homogenous at low incomes levels, it is worth exploring the relationship between behavioral heterogeneity and the manner in which household diversify their spending as they become more affluent. This is because the latter is a necessary (but not a sufficient) condition to observe behavioral heterogeneity in household spending patterns at high levels of income. Put simply, as their affluence grows and a greater

\footnotetext{
${ }^{4}$ This strand of literature refers to the tendency for household spending to become increasingly dispersed across categories as the 'demand for variety' increases. However, this literature does not look at the relationship between quantities and income, but rather expenditure and income. To avoid confusion, we decided not to use this term.
} 
variety goods become available to households, consumption patterns tend to become more unique as households are able to consume a set of goods and services that is increasingly different from that which is consumed by other households.

Several different approaches have been developed in different fields of economics that can help account for the emergent nature of behavioral heterogeneity. For example, within the industrial organization literature, heterogeneity in spending patterns could be linked to the phenomena of product differentiation which is driven by competition and increases number of products available to households (Dixit and Stiglitz, 1977). As household income rises, behavioral heterogeneity could emerge as firms have a greater incentive to produce differentiated goods for wealthy households. This literature tends to adopt the simplifying assumption that the composition of household spending does not fundamentally change as income rises - i.e. preferences are homothetic. This assumption implies that regardless of whether the household is rich or poor, their budget shares on different categories remains constant.

Other scholars have considered how income growth induces systematic changes in household preferences for goods and services. This implies non-homothetic preferences in the sense that the budget shares dedicated to various goods depend on the household's income level, which can help account for heterogeneity across income levels. In terms of why preferences are nonhomothetic, a range of explanations have been offered. Some suggest that time constraints have re-shaped the composition of demand because rising income raises the opportunity cost of consumption (e.g. Gronau and Hamermesh, 2012). Others argue that cognitive constraints play a role as boundedly rational consumers have limited amount of reasoning power to dedicate to consumption decisions (Earl, 1983; Nelson and Consoli, 2010). This implies that households may be increasingly dependent on social institutions or social experts to help inform their decisions (Earl and Potts, 2004), which can be used to explain certain statistical properties of demand (Aversi et al., 1999).

Elsewhere, others argue that households possess innate preferences for a high quality of goods that manifest themselves in spending patterns as the budget constraint becomes more relaxed. In this regard, Bils and Klenow (2001a) used US household expenditure data to estimate "quality Engel Curves" - that examines how the average unit price paid by a household changes as their income changes (proxied by total consumption). They find that across 66 goods which represent 80 per cent of total household expenditure, the quality of household goods tends to increase by 3.7 per cent between 1980 and 1996. If quality growth has been uneven across expenditure categories, then this could explain why spending on some categories has grown faster than in other categories (Bils and Klenow, 2001b). In a similar fashion, some argue that more wealthy households demand a greater variety of goods as they derive utility from jointly consuming these goods with a number of other similar variants (Anderson et al., 1992; Drescher et al., 2008). This approach entertains the possibility that among the basket of goods purchased by the household, some goods are qualitatively inferior to other varieties purchased, but nevertheless purchased for the sake of variety. In a study of UK household data, Jackson (1984) found a positive propensity to consume variety as household income increases. The effect of income on variety consumption was found to be particularly strong among the expenditure categories clothing, transportation and health (Jackson, 1984, p.13). More recently, Drescher et al. (2008) focused on variety consumption of soft drinks, and found that households have positive and significant willingness to pay for more variety in their consumption basket, controlling for the other hedonic characteristics of soft drinks (e.g. calories, minerals and trace elements). 
A fourth strand of literature holds that more fundamental changes in the underlying motivations that drive household consumption behavior are responsible for these trends. A longstanding conjecture is that there exists a hierarchy in demand in that some types of expenditure are of a higher priority than other types of expenditure (Lancaster 1971; Ironmonger 1972; Jackson 1984; Bertola et al, 2006). Low income households will concentrate on high-priority goods, such as food and clothing. As income grows demand for these goods will satiate at some level and the household will begin to diversify its consumption set to include goods of a lower priority. Affluent consumers tend to demand entertainment service to avoid boredom (Scitovsky, 1976), focus on status goods (Heffetz 2011) or other positional goods (Frank 1985). More recently, Witt (2010, 2001) has argued that, besides certain biologically-evolved 'basic needs' that are fixed and universally shared among consumers, others may in fact be acquired through a social learning process, involving an associative learning process. The notion that heterogeneity in consumption patterns may ultimately reflect differences in the underlying needs of consumers may be another important way to account for these fundamental changes in household spending patterns.

\section{Measuring diversity of expenditure shares}

The previous section highlighted the known empirical regularities that govern the manner in which household spending patterns become more diversified as their income grows. At the same time, we also pointed out how differences between households tend also to become larger as household income grows. We contend that these two facts are linked to each other: the tendency for household to diversify their spending as they become more affluent is a necessary, but not sufficient, condition to observe behavioral heterogeneity increase as household income grows. To further explore this link we now turn to explore various methods for measuring household diversity (in this Section) and its relationship to behavior heterogeneity (Section 5)

Within the work that empirically examines the diversity of household spending, a range of different approaches have been used to measure spending diversity. As far as we are aware, no decisive research exists discussing the differences between these measures. In this section we examine the relationship between these different indices and consider the extent to which they produce relatively different empirical results using UK household expenditure data. As there is no single "best" measure our goal is to search for a sense of commonality between alternative techniques, or if no consensus can be found, to isolate the mechanisms that lead to differing empirical findings. 5

The most popular diversity index (see, Gini, 1912, and Simpson, 1949) known as the GiniSimpson index measures the probability that two individuals drawn randomly from a given population belong to two different categories. When looking at the distribution of spending among various expenditure categories, the diversity index would then measure the probability that two dollars drawn randomly from the total amount of expenditures are allocated to two different expenditures categories. In such a case the Gini-Simpson diversity index will be defined as

\footnotetext{
${ }^{5}$ The rule that defines diversity comes from the effect of a transfer of expenditure from one category to another. This is an analogue of the Pigou-Dalton transfer principle taken from the inequality literature. If a household reduces spending in a category where expenditure is high, and in turn increases expenditure in a category with low expenditure, a transfer sensitive measure should show an increase in diversity. Any measure that responds appropriately in all cases is said to be transfer consistent. See Shorrocks and Foster (1987) for details on the transfer principle in the context of inequality measurement.
} 


$$
D_{H}=\sum_{k=1}^{K} s_{k}\left(1-s_{k}\right)
$$

where $s_{k}$ is the share of total expenditures allocated to expenditure category $k$ and $K$ is the total number of such expenditures categories. Expression (1) may evidently be applied to individuals, population deciles or to the population as a whole.

Using (1) we derive that

$$
D_{H}=1-\sum_{k=1}^{K} s_{k}^{2}
$$

so that this diversity index is in fact the complement to 1 of the famous Herfindahl-Hirschman (see, Hirschman, 1945, and Herfindahl, 1950) index (hence the subscript $H$ in $D_{H}$ ) where

$$
H=\sum_{k=1}^{K} s_{k}^{2}
$$

and concentration is a convex (quadratic) and additive function of expenditure shares. Since $H$ is a measure of the inequality ( $H$ is equal to 1 if one spends everything on one category and tends towards zero when all categories have the same weight $(1 / K)$, in which case $H=(1 / K)$ and hence it tends towards 0 when $K \rightarrow \infty$ ), one could use as a measure of diversity any complement to 1 of a bounded inequality measure. Thus any such measures will capture diversity in the sense of the closeness to statistical equality in the expenditure shares.

We may also derive a diversity index from the Theil index. Like most inequality indices, the Theil index amounts to comparing "a priori" shares with "a posteriori" shares. In the case of income inequality the "a priori" shares would be the population shares and the "a posteriori" shares the income shares. For the Theil index the comparison of these two types of shares is made via the logarithmic function. In order to account for the possibility that some shares are equal to 0 , we can only use one of the two definitions of the Theil index, that where it would be defined as

$$
T=\sum_{k=1}^{K} s_{k} \log \frac{s_{k}}{\left(\frac{1}{K}\right)}=\left(\sum_{k=1}^{K} s_{k} \log s_{k}\right)+\log K
$$

If one share is equal to 1 and the other to 0 (maximum inequality), we derive that $T=\log K$.

To obtain a Theil-related measure of diversity we deduct the Theil inequality index from its maximum value. This gives

$$
D_{T H E I L}=\log K-\left[\left(\sum_{k=1}^{K} s_{k} \log s_{k}\right)+\log K\right]=-\left(\sum_{k=1}^{K} s_{k} \log s_{k}\right)
$$

which is simply equal to the entropy, or information content of the shares. This measure thus quantifies diversity as the degree of information content (or surprise) that we would expect to obtain upon realizing that a randomly selected dollar was spent on a particular category ${ }^{6}$.

We could in a similar way derive a diversity index from the Gini index. Since the Gini index has a maximal value of 1 , a Gini-related diversity index $D_{G I N I}$ is the complement to 1 of the Gini

\footnotetext{
${ }^{6}$ If all expenditure goes to one category (such as food) we know with certainty that any randomly selected dollar will come from that share, and hence the information content is zero. This case corresponds to minimal diversity between the shares. Conversely if expenditure is split exactly evenly across the shares then the information content of the selection of a particular share is maximized, as the probability of selecting each share is exactly equal. This corresponds with maximal diversity.
} 
index. There are many algorithms allowing the computation of the Gini index. One of them (see, Silber, 1989) takes a matrix based approach and defines $I_{G I N I}$ as

$$
I_{\text {GINI }}=[\ldots(1 / K) \ldots]^{\prime} G\left[\ldots\left(s_{k}\right) \ldots\right]
$$

where $[\ldots(1 / K) \ldots]^{\prime}$ is a row vector of $K$ elements all equal to $(1 / K),\left[\ldots\left(s_{k}\right) \ldots\right]$ is a column vector of the $K$ expenditure shares, $G$ is a $K$ by $K$ square matrix, called the Gini-matrix (see, Silber, 1989), whose typical element $g_{h l}$ is equal to 0 if $h=l$, to -1 if $l>h$ and to +1 if $h>l$, and the shares $s_{k}$ are ranked by decreasing values of the ratios $\left(s_{k} /(1 / K)\right)$, that is, by decreasing values of the shares $s_{k}$. The diversity index $D_{G I N I}$ would then be defined as

$$
D_{\text {GINI }}=1-\left\{[\ldots(1 / K) \ldots]^{\prime} G\left[\ldots\left(s_{k}\right) \ldots\right]\right\}
$$

To illustrate the three techniques we measure diversity over different expenditure levels using data from the 2001 cross section of the UK Household Expenditure Survey. Our data consists of information on the expenditures of over 5,000 households over 12 different categories. ${ }^{7}$ Each index is calculated for each household and the results are summarized in Figure 1. Rather than plot the individual observations against each other) the relationships between the indices and the total expenditure level are summarized using kernel regressions where each diversity index has been mean standardized such that the relative sensitivities can be assessed.

\section{** FIGURE 1 ABOUT HERE **}

The regressions shown in Figure 1 indicate that diversity in expenditure is low for poorer households and generally increases with total spending. A point of maximal diversity is reached around $180 £$ per week and is very consistent across the three indices. The exact location of this maximal point is difficult to estimate however as there is a stable plateau running from around 150-250£ per week. All three indices show signs of slow decline for high expenditure households, and there is evidence of similar responses of all three regressions to nonlinearities (probably the result of statistical noise) for households spending over $400 £$ per week. In particular all three indices are picking up a sharp decline in expenditure diversity at around $x=450$ and all show a similar spike around $x=550$. These results provide evidence for the notion that there exists a saturation level of spending diversity, as the line appears to flatten out beyond a total expenditure of greater than 200 pounds per week. This suggests that households who reach this level of income do not appear to further diversify their spending across different type of spending categories.

\section{Reference distributions for spending diversity}

The three diversity indices defined previously all assumed, at least implicitly, that maximal diversity would occur if all expenditure shares are equal to $(1 / K)$. Given that the classification of spending patterns into expenditure categories can be arbitrary, such an assumption may not necessarily be reasonable. One may therefore wonder whether it is possible to derive diversity

\footnotetext{
7 The categories are taken from the 2001 UK Family Expenditure Survey and include food, alcohol, clothing and footwear, household goods, domestic services, personal goods and services, travel expenditure, Leisure goods, Entertainment, fuel light and power. The expenditure shares are collectively exhaustive and thus sum to unity.
} 
indices that would be defined with respect to some "a priori" distribution of expenditure shares and which would not be assumed to be maximal when all the shares are equal. Such a comparison amounts to defining diversity when you have two populations, one which is the observed household and another to act as the benchmark. Thus we are looking to produce indices that can now measure the discrepancy between two uneven sets of expenditure shares.

\subsection{Dissimilarity based on the Euclidean distance}

Lieberson $(1964 ; 1969)$ extended the Gini-Simpson concept of population diversity to the case of two populations. Calling respectively $p_{k}$ and $q_{k}$ the proportions of individuals with, say, ethnic groups $k$ in two different cities $(k=1, \ldots, K)$ where $K$ is the total number of ethnic groups, and assuming we randomly draw an individual from each of the two populations, the probability that these two individuals will be of different ethnic groups may be considered as a measure of the diversity between the two populations

$$
D_{B T P}=\sum_{k=1}^{K} p_{k}\left(1-q_{k}\right)=\sum_{k=1}^{K} q_{k}\left(1-p_{k}\right)
$$

The magnitude of this measure of diversity depends however on the extent of within population diversity and hence this needs to be taken into account. We may define the within populations diversity $D_{W T P}$ as

$$
D_{W T P}=\sum_{j=1}^{2}\left(\frac{v_{j .}}{\sum_{j=1}^{2} v_{j .}}\right)\left[\sum_{k=1}^{K}\left(\frac{v_{j k}}{v_{j .}}\right)\left(1-\left(\frac{v_{j k}}{v_{j .}}\right)\right)\right]
$$

where $v_{j k}$ refers to the number of units in population $j$ who belong to category $k$ and $v_{j}=$ $\sum_{k=1}^{K} v_{j k}$ to the total number of units in population $j$.

We can similarly define the diversity in the combined population of both population subgroups as

$$
D_{C P}=\sum_{k=1}^{K}\left\{\left[\left(\sum_{j=1}^{2} v_{j k}\right) /\left(\sum_{j=1}^{2} v_{j .}\right)\right]\left[1-\left[\left(\sum_{j=1}^{2} v_{j k}\right) /\left(\sum_{j=1}^{2} v_{j .}\right)\right]\right]\right\}
$$

Using (9) and (10) a measure of between population subgroups diversity that will take into account the extent of diversity within each of the two subgroups could then be defined as

$$
D_{B}^{\prime}=1-\frac{D_{W T P}}{D_{C P}}
$$

The diversity indices defined in (9), (10) and (11) can evidently be also computed when there are more than two population subgroups, the subscript $j$ running then from 1 to $J$ where $J$ is the total number of population subgroups.

Let us apply this approach to derive a measure of the diversity of the structure of expenditures patterns when comparing the expenditures of $N$ individuals. Let $s_{j k}$ refer to the share in the total expenditures of the whole population of the expenditures of individual $j$ on good $k$, and define respectively $s_{j}$. and $s_{k}$ as $s_{j .}=\sum_{k=1}^{K} s_{j k}$ and $s_{. k}=\sum_{j=1}^{N} s_{j k}$ where $N$ is the total number of individuals and $K$, as before, the total number of expenditure categories. Assuming that $y_{j}$ refers 
to the total expenditures of individual $j$, we can also define $s_{j}$. as $s_{j}=\left(\frac{y_{j}}{\sum_{j=1}^{N} y_{j}}\right)$. This defines the “within individuals” diversity $D_{W I}$ as

$$
D_{W I}=\sum_{j=1}^{N}\left\{\left(s_{j .}\right)\left[\sum_{k=1}^{K}\left(\frac{s_{j k}}{s_{j .}}\right)\left(1-\left(\frac{s_{j k}}{s_{j .}}\right)\right)\right]\right\}
$$

Given that the diversity in expenditures shares in the whole population is actually given by $D_{H}$ in expression (1), we can define the between individuals diversity $D_{B I}$ in the structure of expenditures as $D_{B I}=1-\frac{D_{W I}}{D_{H}}$

or

$$
D_{B I}=1-\frac{\sum_{j=1}^{N}\left\{\left(s_{j .}\right)\left[\sum_{k=1}^{K}\left(s_{j k} / s_{j}\right)\left(1-\left(s_{j k} / s_{j .}\right)\right)\right]\right\}}{\sum_{k=1}^{K} s_{. k}\left(1-s_{. k}\right)}
$$

As stressed by Reardon and Firebaugh (2002) $D_{B I}$ corresponds to Goodman and Kruskal's (1954) $\tau_{B}$ and can be interpreted here as one minus the ratio of the probability that two dollars drawn randomly from the expenditures of an individual are spent on different expenditure categories to the probability that two dollars drawn from the expenditures of the whole population are spent on two different expenditure categories.

Following Teachman (1980) let us now compute the difference DIF between the total diversity $D_{H}$ and the "within individuals" diversity $D_{W I}$. Combining (1) and (12) gives

$$
\begin{aligned}
D I F= & \left(1-\sum_{k=1}^{K} s_{. k}^{2}\right)-\sum_{j=1}^{N}\left\{\left(s_{j .}\right)\left[\sum_{k=1}^{K}\left(\frac{s_{j k}}{s_{j .}}\right)\left(1-\left(\frac{s_{j k}}{s_{j .}}\right)\right)\right]\right\} \\
\leftrightarrow & \leftrightarrow I F=\left[\sum_{j=1}^{N}\left\{\left(s_{j .}\right)\left[\sum_{k=1}^{K}\left(\frac{s_{j k}}{s_{j .}}\right)^{2}\right]\right\}\right]-\left[\sum_{k=1}^{K} s_{. k}^{2}\right] \\
& \leftrightarrow D I F=\sum_{j=1}^{N}\left(\frac{1}{s_{j .}}\right)\left[\sum_{k=1}^{K}\left(s_{j k}^{2}-\left(s_{j .}^{2} s_{. k}^{2}\right)\right)\right]
\end{aligned}
$$

Equation (16) may be also expressed as

$$
D I F=\sum_{j=1}^{N}\left(\frac{1}{s_{j .}}\right)\left[\sum_{k=1}^{K}\left(s_{j k}-\left(s_{j .} S_{. k}\right)\right)^{2}\right]
$$

Expression (17) shows the link between the concept of "between individuals" diversity (since DIF refers to the difference between total and "within individuals" diversity) and the concept of independence between the individuals and the shares of the various expenditure categories (the squared Euclidean distance $\left(s_{j k}-\left(s_{j .} s_{. k}\right)\right)^{2}$ really amounts to measuring the degree of such a potential dependence). We should also stress that the weight $\left(\frac{1}{s_{j}}\right)$ which appears in (17) is also the weight which is attached to the Euclidean distance in correspondence analysis, a kind of principal components analysis which is specific to contingency tables.

Finally, and most importantly, note that (16) may be also expressed as

$$
D I F=\sum_{j=1}^{N}\left(s_{j .}\right) \sum_{k=1}^{K}\left[\left(\frac{s_{j k}}{s_{j .}}\right)-s_{. k}\right]^{2}
$$


In other words this difference is equal to the weighted average, the weights being the shares of the individuals in the total expenditures of the population, of the squared Euclidean distance between the set of the shares that these individuals spend on the various expenditures categories and the corresponding set of shares for the population as a whole. Expression (18) could therefore be considered as a measure $D I S_{E u c}=D I F$ of the dissimilarity between the patterns of expenditures of the different individuals. The squared Euclidean distance is just one way of measuring the distance between the structure of expenditures of an individual and that of the population as a whole. The following section will suggest alternative ways of measuring such a distance.

\subsection{Dissimilarity based on the absolute value function}

Instead of using the Euclidean distance we can evidently replace the square function in (18) by an absolute value and define an alternative dissimilarity index $D I S_{\text {abslolute value }}{ }^{8}$ as

$$
D I S_{\text {absolute value }}=\sum_{j=1}^{N}\left(s_{j .}\right) \sum_{k=1}^{K}\left|\left(\frac{s_{j k}}{s_{j .}}\right)-s_{. k}\right|
$$

Expression (19) reminds us of the famous Duncan and Duncan (1955) index of segregation and of Pietra’s (1915) dissimilarity index. In fact (19) may be also expressed as

$$
D I S_{\text {absolute value }}=\sum_{j=1}^{N}\left(s_{j .}\right) \sum_{k=1}^{K} s_{. k}\left|\left(\left(\frac{s_{j k}}{s_{j .}}\right) / s_{. k}\right)-1\right|
$$

Remembering that (20) measures the difference between the diversity of expenditures patterns in the whole population and the "within individuals diversity", we can standardize DIS absolute value by dividing it by the diversity in the whole population and derive a standardized measure of diversity DIS absolute value

$$
\text { DIS } S_{\text {absolute value }}^{\text {standardized }}=(1 / 2)\left\{\left[\sum_{j=1}^{N}\left(s_{j .}\right) \sum_{k=1}^{K} s_{k}\left|\left(\left(\frac{s_{j k}}{s_{j .}}\right) / s_{. k}\right)-1\right|\right] /\left[1-\sum_{k=1}^{K} s_{. k}^{2}\right]\right\}
$$

Such a measure has been proposed by Reardon and Firebaugh (2002) as a measure of multi-group segregation. Note that, as these authors did, we introduced a coefficient (1/2) to make sure that the dissimilarity index DIS absolute value varied between 0 and 1.

The absolute value and the square functions are however not the only ways of measuring a distance between the two distributions of spending patterns, that represented by the vector of individual shares $\left(s_{j k} / s_{j}\right.$. $)$ and that corresponding to the vector of the spending shares $s_{. k}$ in the whole population.

\subsection{Dissimilarity derived from the concept of entropy}

Using the concept of entropy, Theil (1967) derived a measure of change in expected information that can again be applied to the comparison of the set of the individuals shares $\left(s_{j k} / s_{j}\right)$ and of the population shares $s_{. k}$. One can define two Theil-related measures of dissimilarity, $D I S_{\text {Theil }}$ and DIS Theil (which would be parallel to the measures of dissimilarity given in (19) and (20) ), as

\footnotetext{
${ }^{8}$ Indices based upon the absolute value need not be transfer consistent. See for example Cowell (1988).
} 


$$
\begin{gathered}
D I S_{\text {Theil }}=\sum_{j=1}^{N}\left(s_{j .}\right) \sum_{k=1}^{K}\left(s_{j k} / s_{j .}\right) \log \frac{\left(s_{j k} / s_{j .}\right)}{\left(s_{. k}\right)} \\
D I S_{\text {Theil }}^{\prime}=\sum_{j=1}^{N}\left(s_{j .}\right) \sum_{k=1}^{K} s_{. k} \log \frac{s_{. k}}{\left(s_{j k} / s_{j .}\right)}
\end{gathered}
$$

One may also define two "standardized Theil-related measure of dissimilarity", DIS Theil and DIS ${ }_{\text {Theil }}^{\text {standized }}$, which would be parallel to the measures given in (13) and (21) and would measure the "between individuals" dissimilarity in spending patterns. Moe precisely we would express these standardized indices as

$D I S_{\text {Theil }}^{\text {standardized }}=\left[\sum_{j=1}^{N}\left(s_{j .}\right) \sum_{k=1}^{K}\left(s_{j k} / s_{j .}\right) \log \frac{\left(s_{j k} / s_{j}\right)}{\left(s_{. k}\right)}\right] /\left(-\left[\sum_{k=1}^{K} s_{. k} \log s_{. k}\right]\right)$

and

$D I S_{\text {Theil }}^{\text {standrdized }}=\left[\sum_{j=1}^{N}\left(s_{j .}\right) \sum_{k=1}^{K} s_{. k} \log \frac{s_{. k}}{\left(s_{j k} / s_{j .)}\right)}\right] /\left(-\left[\sum_{k=1}^{K} s_{. k} \log s_{. k}\right]\right)$

Note that expression (24) has been proposed by Reardon and Firebaugh (2002) as a measure of multi-group segregation and expression (22) which was originally proposed by Theil and Finizza (1971) has been used by Mora and Ruiz-Castillo (2003) in their study of additive decomposable segregation indexes.

We now illustrate the measures of spending diversity based upon a reference group, where our reference is the average household expenditure on each class of good. Figure 2 gives the squared Euclidian distances between each household's expenditure shares and the average of those shares for the entire population, such that an expenditure weighted average is equal to $D_{W I}$. The greater value in the vertical axis, the greater the diversity the household's expenditure pattern - not from equal shares but from the sample average shares. The same is true for Figure 3 which marks distance in terms of the absolute value function and Figure 4 which is Theil's entropy divergence.

\section{** FIGURES 2, 3 AND 4 ABOUT HERE **}

In the cases of all three Figures a regression line is added to illustrate the relationships between total expenditure and distance. A comparison shows that the different metrics are similar in the manner in which they capture household spending diversity. Low income households have consumption baskets which are markedly different from that of the sample average; however these baskets become closer to the representative household as income increases. This result is intuitive as a household with an expenditure level around the sample average would more closely resemble the 'average household' in terms of expenditure shares. Beyond this minimal point all three measures give a qualitatively similar increase in the distance between a household's consumption basket and the sample average as expenditure rises, indicating increasing diversity with income relative to this benchmark. This result is therefore consistent with the earlier argument of increasing diversity with income, albeit limited to middle and higher income earners.

Concerning the relationship between spending diversity and the emergence of heterogeneity, it is of interest to note that at lower income levels, most observations are densely located around the average level of household diversity, as shown by the regression line. This implies that at low income levels, there is relatively less heterogeneity in the population and there is a relatively close relationship between the extent to which households diversify their spending and their 
income level. On the other hand, at high income levels (above a total expenditure level of around 200 pounds per week), it appears that observations are more widely dispersed around the regression line, which suggests that the heterogeneity in spending patterns has grown. This is evident in the widening standard errors (depicted with the dashed lines) around the regression model in Figures 2-4.

\section{Conclusion}

As households reach ever higher levels of wealth, understanding how they diversify their spending can provide some important insights into how the global economy will continue to evolve. Apart from this, insights about households diversify their spending can also help inform models of behavioral heterogeneity in demand. This paper has reviewed the empirical facts that are known about how households diversify their spending as they become more affluent, the underlying behavior tendencies that are thought to drive this process, as well as clarified the different approaches to measuring household spending diversity.

In terms of measuring household spending diversity, we have described the relationship between the major measures of diversity used in the literature. This has included the Gini-Simpson index, the entropy or information content of expenditure shares and the Gini Coefficient. Results indicate that there are strong similarities between the three measures and hence empirical results should be insensitive to the choice of index. We also considered measures of diversity that consider a non-equal reference distribution such as the squared Euclidian distance, the absolute distance and an information theoretic divergence. Again similar results were obtained across the measures.

In terms of understanding the link between how households diversify their spending as their income grows and the emergence of behavioral heterogeneity, our results show some preliminary evidence that there is relatively close relationship between these two phenomena. We found that, at low income levels, household have relatively concentrated spending patterns but tended to

diversify as their income rises. At the same time, the level of heterogeneity in expenditure diversity grew with income.

\section{References}

Allen, R. G. D., \& S. A. L. Bowley (1935). Family expenditure: a study of its variation (No. 2). P.S. King.

Anderson, S.P., A. de Palma and J. F. Thisse 1992. Discrete Choice Theory of Product Differentiation. MIT Press, Cambridge, Mass.

Attanasio, O. P. (1999). Consumption. Handbook of Macroeconomics, 1, 741-812.

Aversi R, G. Dosi, G. Fagiolo, M. Meacci and C. Olivetti (1999) "Demand dynamics with socially evolving preferences," Industrial and Corporate Change 8:2.

Banerjee, A. V. and E. Duflo (2007) "The Economic Lives of the Poor," Journal of Economic Perspectives, 21(1): 141-168.

Banks, J. R. Blundell and A. Lewbel (1997) "Quadratic Engel Curves and Consumer Demand," The Review of Economics and Statistics, 79(4):527-539. 
Banks, J., R. Blundell, R. and A. Lewbel (1997) "Quadratic Engel Curves and Consumer Demand," Review of Economics and Statistics 79(4): 527-539.

Barigozzi, M., \& Moneta, A. (2012). Identifying the Independent Sources of Consumption Variation. LEM Working Paper 2012/16,

Barnett, W. A., \& Serletis, A. (2008). Consumer preferences and demand systems. Journal of Econometrics, 147(2), 210-224.

Barro, R. and X. Sala-i-Martin (1995), Economic Growth. New York: McGraw Hill.

Beckert, W. and Blundell, R. (2008). "Heterogeneity and the Non-Parametric Analysis of Consumer Choice: Conditions for Invertibility." Review of Economic Studies, 75(4), 1069-1080.

Bertola, G., R. Foellmi and J. Zweimüller (2006) Income Distribution in Macroeconomic Models. Cambridge, MA: Princeton University Press.

Bierens, H.J., and H.A. Pott-Butler (1990) "Specification of Household Engel Curves by Nonparametric Regression," Econometric Reviews 9 :123-184.

Bils, M. and P. J. Klenow (2001a) "Quantifying Quality Growth," American Economic Review 91 (4): 1006-1030.

Bils, M. and P. J. Klenow (2001b) "The acceleration in variety growth," American Economic Review 91(2): 274-280.

Blaug, M. (1992) The methodology of economics: Or, how economists explain. Cambridge, UK: Cambridge University Press.

Blow, L., A. Leicester and Z. Oldield (2004) "Consumption Trends in the UK: 1975-99,". Institute for Fiscal Studies, London.

Blundell, R. (2005). How revealing is revealed preference?. Journal of the European Economic Association, 3(2-3), 211-235.

Blundell, R. and T. M. Stoker (2005) "Heterogeneity and aggregation," Journal of Economic Literature 43(2): 347-391.

Brown, A., \& Deaton, A. (1972). Surveys in applied economics: models of consumer behaviour. The Economic Journal, 82(328), 1145-1236.

Browning, M., \& Collado, M. D. (2007). Habits and heterogeneity in demands: a panel data analysis. Journal of Applied Econometrics, 22(3), 625-640.

Calvet, L. and E. Common (2003) "Behavioral Heterogeneity and the Income Effect," Review of Economics and Statistics 85(3): 653-669.

Chai, A. and A. Moneta (2012) "Back to Engel? Some evidence for the hierarchy of needs," Journal of Evolutionary Economics 1-28.

Chai, A. and A. Moneta (2010) "Retrospectives: Engel Curves," Journal of Economic Perspectives 24 (1): 225-240.

Christensen, M (2007) "Integrability of Demand Accounting for unobservable heterogeneity: a test on panel data” Institute of Fiscal Studies Working Paper Nr 07/14.

Clements, K. W., A. Selvanathan and S. Selvanathan (1996a) “Applied Demand Analysis: A Survey,” Economic Record 72(216): 63-81.

Clements, K., and D. Chen (1996b) "Fundamental Similarities in Consumer Behavior," Applied Economics 28: 747-757.

Clements, K. and S. Selvanathan (1994) "Understanding Consumption Patterns," Empirical Economics 19: 69-110.

Clements, K.W, Yanrui Wu and Jing Zhang (2006) "Comparing international consumption patterns,” Empirical Economics 31(1): 1-30. 
Cowell, F. A. (1988). "Inequality decomposition: three bad measures.” Bulletin of Economic Research, vol. 40, PP 309-12.

de Villemeur, E. B. (1999) "Aggregation of demand and distribution of characteristics: A difficulty in modelling behavioral heterogeneity," Université de Cergy-Pontoise: Document de travail, 99, 38.

Deaton, A. (1987) "Consumption" in New Palgrave Dictionary of Economics, 1st edition, Palgrave Macmillan.

Deaton, A. (1980A). Economics and consumer behaviour. Cambridge university press.

Deaton, A. and J. Muellbauer (1980B) "An almost ideal demand system," American Economic Review 312-326.

Dixit, A. K. and J. E. Stiglitz (1977) "Monopolistic competition and optimum product diversity," American Economic Review 297-308.

Drescher, L., S. Thiele and C. R. Weiss (2008) "The taste for variety: A hedonic analysis," Economics Letters 101(1): 66-68.

Duncan, O.D. and B. Duncan (1955) “A methodological analysis of segregation indices," American Sociological Review 20(2): 210-217.

Earl, P. (1983) The Economic Imagination. Wheatsheaf Books, Brighton.

Earl P. and J. Potts (2004) "The market for preferences," Cambridge Journal of Economics 28:619-633.

Engel, E. (1857) Die Produktions- und Consumtionsverhältnisse des Königreichs Sachsen, Anlage I, 1-54. Reprinted in Engel, E. (1895) "Die Lebenskosten belgischer Arbeiterfamilien früher und jetzt”, Bulletin de l'Institut International de Statistique 9: 1124.

Falkinger, J. and J. Zweimüller (1996) "The cross-country Engel curve for product diversification," Structural Change and Economic Dynamics 7: 79-97.

Foellmi, R. and J. Zweimüller (2008) "Structural Change, Engel's Consumption Cycles and Kaldor's Facts of Economic Growth," Journal of Monetary Economics 55 (2): 1317-1328.

Frank, R. H. (1985) "The Demand for Unobservable and Other Nonpositional Goods," American Economic Review 75:101-116.

Gilbert, C. L. (1991) "Do Economists Test Theories? Demand Analysis as Tests of Theories of Economic Methodology," in N. de Marchi and M. Blaug, Appraising Economic Theories. Studies in the Methodology of Research Programs, pp. 137- 168.

Gini, C. W. (1912) "Variabilita e mutabilita," Studi Economico-Giuridici della R. Universita di Cagliari 3: 3 - 159.

Goodman, L. and W. H. Kruskal (1954) "Measures of Association for Cross-Classifications," Journal of the American Statistical Association 49: 732-764.

Gorman, W. M. (1981), "Some Engel Curves," in Essays in the Theory and Measurement of Consumer Behaviour in Honor of Sir Richard Stone, ed. By Angus Deaton, Cambridge: Cambridge University Press.

Grandmont, J. M. (1987) "Distribution of preferences and the 'law of demand'," Econometrica 55, 155-161.

Grandmont, J.-M (1992) "Transformations of the Commodity Space, Behavioral Heterogeneity, and the Aggregation Problem," Journal of Economic Theory 57: 1-35.

Gronau, R. and D. S. Hamermesh (2008) "The demand for variety: A household production perspective," The Review of Economics and Statistics 90(3): 562-572. 
Grossman, G. and E. Helpman (1991) Innovation and Growth in the Global Economy, Cambridge University Press.

Hallak, J. (2010) "A Product-Quality View of the Linder Hypothesis," Review of Economics and Statistics 92( 3): 453-466.

Heckman, J. J. (2001) "Micro data, heterogeneity, and the evaluation of public policy: Nobel lecture," Journal of Political Economy 109(4): 673-748.

Heffetz, O. (2011) "A Test of Conspicuous Consumption: Visibility and Income Elasticities," The Review of Economics and Statistics 93 (4): 1101-1117.

Herfindahl, O. C. (1950) Concentration in the U.S. Steel Industry. Unpublished doctoral dissertation, Columbia University.

Hicks, J.R. (1956) A Revision of Demand Theory. Oxford University Press.

Hildenbrand, K. and R. John (2003) On parametrization in modelling behavioral heterogeneity. Institute of Economics, University of Copenhagen.

Hildenbrand, K. (1998) "On J. M. Grandmont's Modelling of Behavioral Heterogeneity," Bonn Discussion Paper, A-580.

Hildenbrand, W. and A. Kneip (1999) "On Behavioral Heterogeneity," Bonn Discussion Paper, A-589.

Hildenbrand, W. (1994) Market Demand: Theory and Empirical Evidence Princeton University Press.

Hirschman, A. 0. (1945) National power and the structure of foreign trade. Berkeley.

Houthakker, H.S. (1957) "An international comparison of household expenditure patterns," Econometrica 25: 532-51.

Ironmonger, D. S. (1972) New commodities and consumer behavior. Cambridge: Cambridge University Press.

Jackson, L. (1984) "Hierarchic Demand and The Engel Curve for Variety," Review of Economics and Statistics 66 (1): 8-15.

Kneip, A. (1999) "Behavioral Heterogeneity and Structural Properties of Aggregate Demand," Journal of Mathematical Economics 31: 49-79.

Kuznets, S. (1973) "Modern economic growth: findings and reflections," American Economic Review 63(3): 247-258.

Lancaster, K. (1971) Consumer demand: a new approach. NY: Columbia University Press.

Lebergott, S. 1993 "Pursing Happiness- American Consumers in the Twentieth Century. Princeton University Press, Princeton.

Lewbel, A. (2008) "Engel Curves," in New Palgrave Dictionary of Economics, 2nd edition, Palgrave Macmillan.

Lewbel, A. (2005) "Modelling Heterogeneity,” Boston College Working Papers in Economics 650, Boston College, Department of Economics.

Lewbel A. (2001) "Demand Systems with and without Errors," American Economic Review 91: 611-618

Lewbel, A. (1991) "The Rank of Demand Systems: Theory and Nonparametric Estimation," Econometrica 59:711-730.

Lewbel, Arthur. "A rational rank four demand system." Journal of Applied Econometrics 18.2 (2003): 127-135.

Li, G., H. Song and S. F. Witt (2004) "Modeling tourism demand: A dynamic linear AIDS approach," Journal of Travel Research 43(2): 141-150. 
Lieberson, S. (1964) "An extension of Greenberg's linguistic diversity measures," Language 40: 526-531.

Lieberson, S. (1969) “Measuring Population Diversity,” American Sociological Review 34:85062.

Mirowski, P. and D. W. Hands (2006) Agreement on demand: consumer theory in the twentieth century. Durham: Duke University Press.

Mora, R. and J. Ruiz-Castillo (2003) "Additively decomposable segregation indexes. The case of gender segregation by occupations and human capital levels in Spain," Journal of Economic Inequality 1: 147-179.

Nelson R. and D. Consoli (2010) "An evolutionary theory of household consumption behavior," Journal of Evolutionary Economics 20:665-687.

Pietra, G. (1915) "Delle relazioni tra gli indici di variabilita (I, II)," Atti del Reale Istituto Veneto di Scienze, Lettere ed Arti, a.a. 1914-15, tomo LXXIV, parte II, 775-804.

Prais, S. J. (1953) "Non-linear Estimates of the Engel Curve," Review of Economic Studies 2087.

Prais, S. J. and H. S. Houthakker (1955) The analysis of family budgets (Vol. 4). Cambridge University Press.

Quah, J. (1997) "The Law of Demand when Income is Price Dependent," Econometrica 65(6): 1421-1442.

Reardon, S. F. (2009) "Measures of Ordinal Segregation," in Y. Flückiger, S. F. Reardon and J. Silber, editors, Occupational and Residential Segregation, volume 17 of Research on Economic Inequality, Emerald, Bingley, UK, pages 129-155.

Reardon, S. F. and G. Firebaugh (2002) "Measures of Multigroup Segregation," Sociological Methodology 32(1): 33-67.

Romer, P. (1990) "Endogenous Technological Change," Journal of Political Economy 98(5): 71102.

Ryan D. and T. Wales (1999) "Flexible and Semi-flexible Consumer Demands with Quadratic Engel Curves," The Review of Economics and Statistics 81(2): 277-287.

Scitovsky, T. (1976) The Joyless Economy. The Psychology of Human Satisfaction. Oxford University Press.

Shorrocks, A. and Foster, J. (1987) “Transfer Sensitive Inequality Measures" Review of Economic Studies, 54, 485-497.

Silber, J. (1989) "Factors Components, Population Subgroups and the Computation of the Gini Index of Inequality," The Review of Economics and Statistics, LXXI:107-115.

Slottje, D. (2009) Quantifying Consumer Preferences. Bingley: Emerald.

Simpson, E. H. (1949). "Measurement of Diversity,” Nature 163: 688.

Stigler, G. J. (1954) "The early history of empirical studies of consumer behavior," Journal of Political Economy 62(2): 95-113.

Teachman, J. D. (1980) "Analysis of Population Diversity: Measures of Qualitative Variation," Sociological Methods and Research, 8: 341-362.

Theil, H., C. F. Chung and J. L. Seale (1989) International evidence on consumption patterns (Vol. 1) JAI Press.

Theil, H, and R. Finke (1983). "The Consumers Demand for Diversity,” European Economic Review 23: 395-400.

Theil, H. and A. J. Finizza (1971) "A note on the measurement of racial integration of schools by means of information concepts," Journal of Mathematical Sociology 1: 187-194.

Theil H. (1967) Economics and information theory. Amsterdam: North-Holland, 1967. 
Thomas, D. and J. Strauss (1997) "Health and wages: Evidence on men and women in urban Brazil," Journal of Econometrics 77(1): 159-185.

US Department of Labor. 2006. 100 Years of US Consumer Expenditure. Report 991.

Witt, U. (2001) "Learning to consume - a theory of wants and the growth of demand," Journal of Evolutionary Economics 11:23-36.

Witt, U. (2010) "Product characteristics, innovations and the evolution of consumption.A behavioral approach," paper prepared for the conference on "Technical change: history, economics and policy” in honor of G. N. Tunzelmann, SPRU, March 2010.

Working, H. (1943) "Statistical laws of family expenditure," Journal of the American Statistical Association 38(221): 43-56.

\section{Tables and Figures}

Table 1: Sample of US annual consumption expenditure shares, 1901 and 2003.

\begin{tabular}{|c|c|c|c|c|c|}
\hline \multirow[t]{2}{*}{ Expenditure Category } & 1901 & \multicolumn{3}{|c|}{2003} & Change in \\
\hline & US\$ & $\begin{array}{c}\text { budget } \\
\text { share }\end{array}$ & US\$ & budget share & $\begin{array}{r}\text { Expendiutre } \\
\text { share }\end{array}$ \\
\hline Food & 327 & 42.5 & 5,357 & 13.1 & -29.4 \\
\hline Alcoholic beverages & 12 & 1.6 & 384 & 0.9 & -0.7 \\
\hline Housing & 179 & 23.3 & 13,359 & 32.8 & +9.5 \\
\hline Apparel and Services & 108 & 14 & 1,694 & 4.2 & -9.8 \\
\hline Transportation* & NA & NA & 7,770 & 19.1 & NA \\
\hline Healthcare & 40 & 5.2 & 2,384 & 5.9 & +0.7 \\
\hline Entertainment & 12 & 1.6 & 2,069 & 5.1 & +3.5 \\
\hline Personal care products and services & NA & NA & 526 & 1.3 & NA \\
\hline Reading and Education & 8 & 1.1 & 901 & 2.1 & + \\
\hline Tobacco & 11 & 1.4 & 305 & 0.7 & -0.7 \\
\hline Charity Contribution & 10 & 1.3 & 1,324 & 3.2 & +1.9 \\
\hline Expenditure, all items & 769 & & 40,748 & & $+5,198$ \\
\hline
\end{tabular}

Source: US Department of Labor 2006. 1901 estimate for Transportation and Personal Car products and services were not reported in the BLS as these were reported in a 'miscellaneous' category. As a rough estimate Lebergott (1993) estimates per capita personal consumption of transport in 1901 to be 4.3 per cent of budget share and personal care expenditure in 1901 to represent less than 1 per cent of the budget share 
Figure 1. Kernel Regression of Diversity Indices against Total Household Expenditure

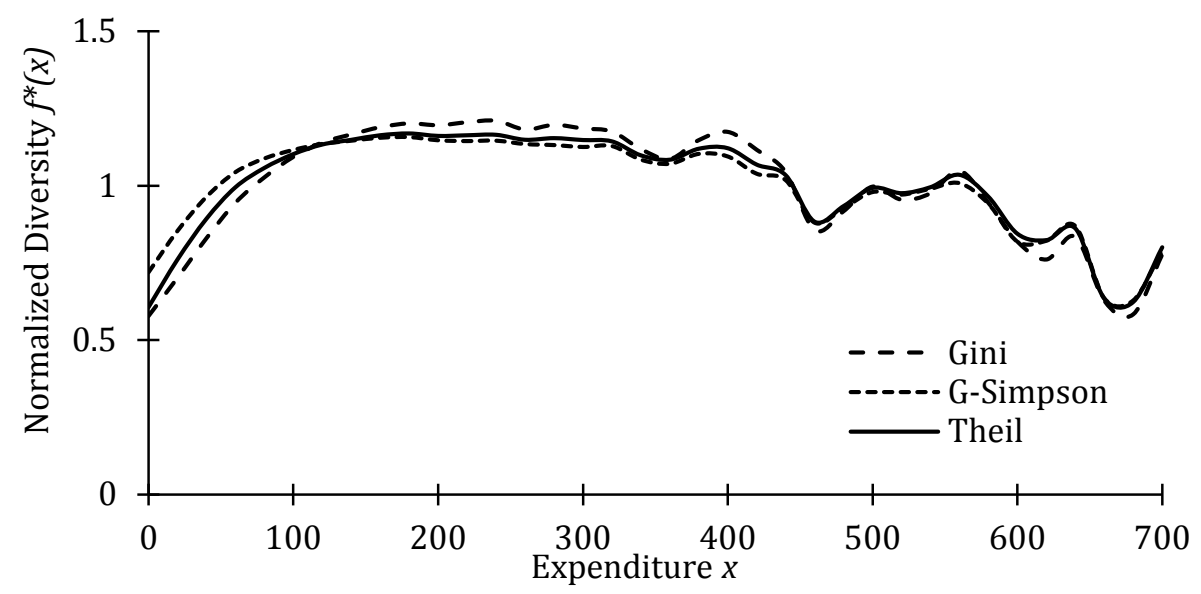

Note: The horizontal axis gives weekly household expenditure $(£)$ and the vertical axis is a normalized diversity scale.

Figure 2. Squared Euclidian Distances: Expected Shares and Total Expenditure.

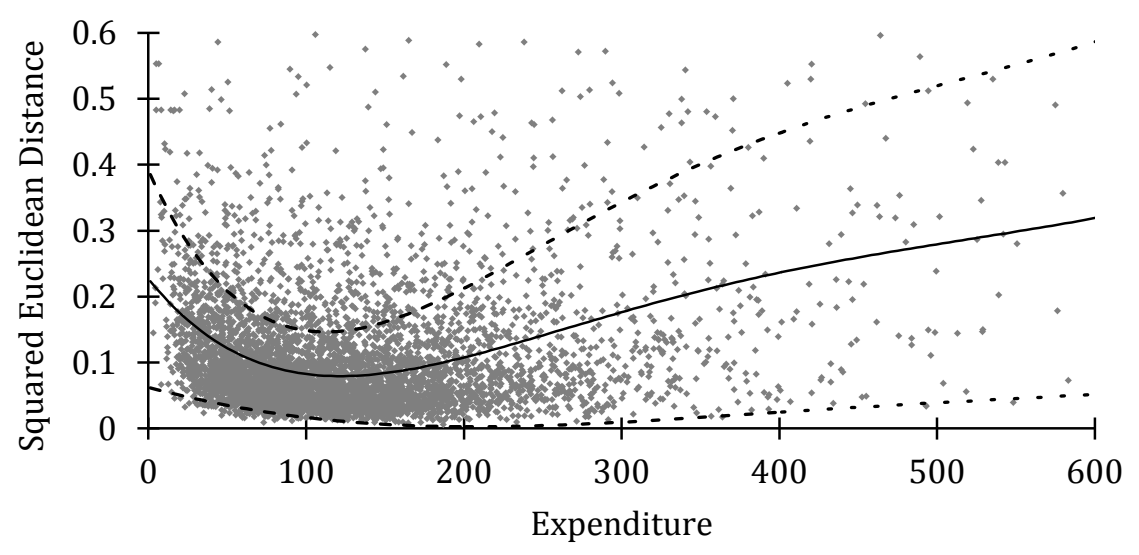

Note: The horizontal axis gives the total household expenditure while the vertical axis gives the squared Euclidean distance from the household shares to the expected shares. Dashed lines give standard deviations. 
Figure 3. Absolute Distances: Expected Shares and Total Expenditure.

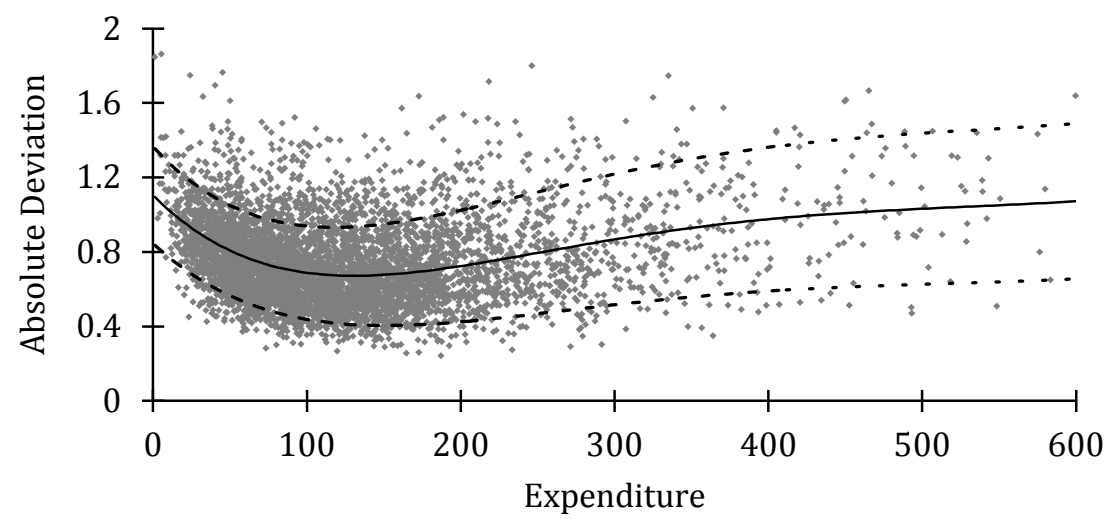

Note: The horizontal axis gives the total household expenditure while the vertical axis gives the absolute distance from the household shares to the expected shares. Dashed lines give standard deviations.

Figure 4. Theil Divergences: Expected Shares and Total Expenditure.

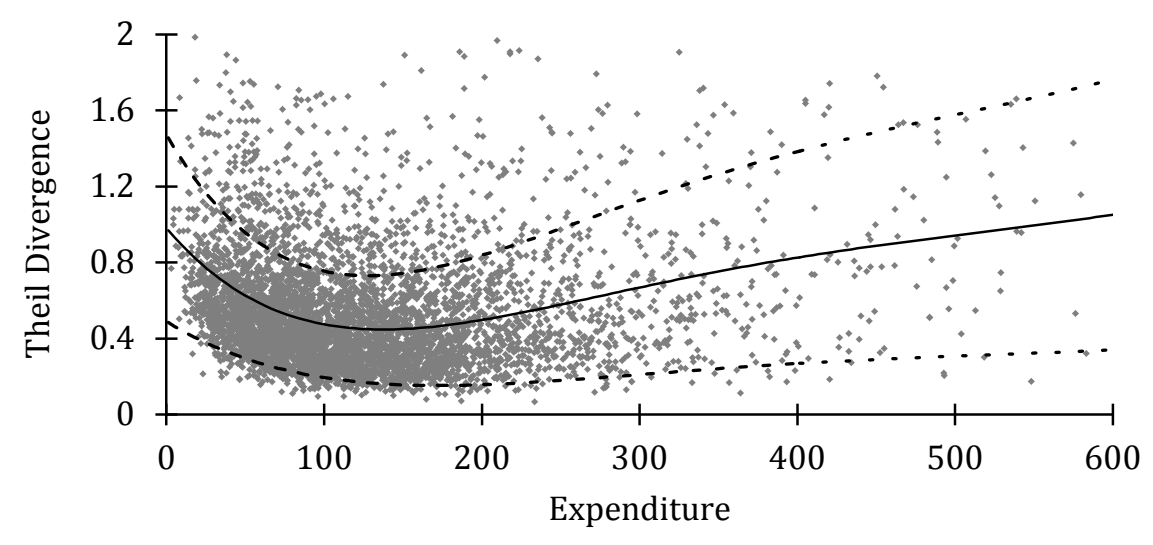

Note: The horizontal axis gives the total household expenditure while the vertical axis gives the Theil Divergence from the household shares to the expected shares. Dashed lines give standard deviations.

\section{Acknowledgements}

Parts of this paper were presented at International Schumpeter Society Conference, $2-5^{\text {th }}$ of July, Brisbane and the Griffith EPAP workshop on Economic Development and Inequality, 12th July 2012. We thank the conference and workshop participants for their comments. We thank the UK Economic and Social Data Service (ESDS) and the UK Data Archive for providing access to data from the UK Household Expenditure Survey. The usual disclaimer applies. 